Suryoaji, et al/Jurnal Ekonomi Syariah Teori dan Terapan Vol. 6 No. 9 September 2019: 1877-1893; KOMPARASI EFISIENSI \& PRODUKTIVITAS PERUSAHAAN ASURANSI JIWA KONVENSIONAL DAN SYARIAH DI INDONESIA PADA TAHUN 2014 - 2017, DENGAN PENDEKATAN DEA \& INDEKS MALMQUIST

\title{
KOMPARASI EFISIENSI \& PRODUKTIVITAS PERUSAHAAN ASURANSI JIWA KONVENSIONAL DAN SYARIAH DI INDONESIA PADA TAHUN 2014 - 2017, DENGAN PENDEKATAN DEA \& INDEKS MALMQUIST ${ }^{1}$
}

\author{
Oky Suryoaji \\ Departemen Ekonomi Syariah-Fakultas Ekonomi dan Bisnis-Universitas Airlangga \\ Email: okysuryo777@gmail.com \\ Eko Fajar Cahyono \\ Departemen Ekonomi Syariah-Fakultas Ekonomi dan Bisnis-Universitas Airlangga \\ Email: fajars2ie2gmail.com
}

\begin{abstract}
:
Tujuan penelitian ini adalah untuk mengetahui tingkat efisiensi dan produktivitas perusahaan asuransi jiwa antara konvensional dan syariah (baik Unit Usaha Syariah maupun Full Fledge) periode 2014 - 2017. Penelitian ini menggunakan pendekatan kuantitatif dengan metode non parametrik DEA (Data Envelopment Analysis) yang dilandaskan dengan asumsi CRS (Constant Return to Scale) dan VRS (Variable Return to Scale) dan Indeks Malmquist asumsi TFPC (Total Factor Productivity Change) dengan diolah menggunakan aplikasi DEAP Versi 2.1. Variabel yang digunakan meliputi Total Aset, Beban, Klaim, Premi/Dana Tabrru', dan Pendapatan. Subjek yang digunakan dalam penelitian ini sebanyak 29 perusahaan asuransi jiwa syariah yang terdiri 10 perusahaan asuransi jiwa syariah dan 19 perusahaan asuransi jiwa konvensional. Hasil penelitian menunjukkan bahwa rata-rata perusahaan asuransi jiwa konvensional dan syariah belum mencapai efisien (CRS) dan rata-rata TFPC perusahaan asuransi jiwa konvensional sudah mencapai produktivitas sementara syariah belum mencapai produktivitas.
\end{abstract}

Keywords:Asuransi Jiwa Syariah, Efisiensi, Produktivitas, Data Envelopment Analysis (DEA), Constant Return to Scale (CRS), Variable Return to Scale (VRS), Malmquist Index (MI), Total Factor Productivity Change (TFPC).

\section{PENDAHULUAN}

Dalam budaya suku arab, praktik asuransi tumbuh pada zaman Nabi Muhammad saw yang disebut aqilah. AlAqilah mengandung pengertian saling memikul dan bertanggung jawab bagi keluarga.Dalam kasus terbunuhnya seorang anggota keluarga, ahli waris korban akan mendapatkan vang darah (diyat) yang dibayarkan oleh angota keluarga terdekat dari si pembunuh yang disebut aqilah. Aqilah mengumpulkan dana secara bergotong-royong untuk membantu keluarga yang terlibat dalam perkara pembunuhan yang tidak sengaja itu. Dalam satu kasus tentang aqilah ini, Nabi Muhammad saw pernah bersabda seperti yang diriwayatkan oleh Abu Hurairah ra, yang artinya adalah sebagai berikut.

Dari Abu Hurairah ra: "Berselisih dua orang wanita dari suku Huzail, kemudia salah satu wanita tersebut melempar batu kepada wanita yang lain sehingga mengakibatkan kematian wanita tersebut beserta janin yang dikandungnya. Ahli waris dari wanita yang meninggal tersebut mengadukan

\footnotetext{
${ }^{1}$ Jurnal ini merupakan bagian dari skripsi ditulis oleh Oky Suryoaji, NIM : 041411431052 , yang diuji pada tanggal 25 Juni 2019.
} 
Suryoaji, et al/Jurnal Ekonomi Syariah Teori dan Terapan Vol. 6 No. 9 September 2019: 1877-1893; KOMPARASI EFISIENSI \& PRODUKTIVITAS PERUSAHAAN ASURANSI JIWA KONVENSIONAL DAN SYARIAH DI INDONESIA PADA TAHUN 2014 - 2017, DENGAN PENDEKATAN DEA \& INDEKS MALMQUIST

peristiwa tersebut kepada Rasulullah SAW maka Rasulullah memutuskan ganti rugi dari pembunuhan terhadap janin adalah dengan membebaskan seorang budak laki-laki atau wanita.Dan kompensasi atas kematian wanita tersebut dengan uang darah (diyat) yang dibayarkan oleh aqilahnya (kerabat dari orang tua lakilaki)." (HR. Bukhari)

Didalam Al-Quran terdapat sebuah perintah Allah swt untuk saling melindungi dalam keadaan susah dalam Surat Al-Quraisy (106) ayat 4,

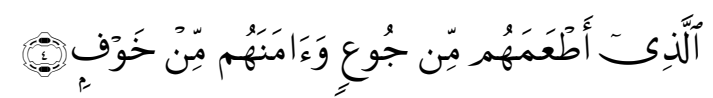

Allazi at'amahum min ju'inw-wa-aamana hum min khawf

Artinya: "Yang telah memberi makanan kepada mereka untuk menghilangkan lapar dan mengamankan mereka dari rasa ketakutan".

Dalam penjelasan ayat diatas dapat kita ketahui bersama bahwa, Allah swt telah menganjurkan kita untuk saling tolong-menolong dalam segala hal serta melindungi sesama manusia dari rasa ketakutan. Baik ketakutan karena kelaparan,tempat tinggal ataupun ketika ajal menjemput, ayat tersebut cocok dan sesuai dengan konsep asuransi syariah yang berlandaskan pada akad tabarru (sosial/tolong-menolong).Dewasa ini, asuransi menjadi salah satu industri kevangan yang memiliki peran dalam kehidupan dan atau kebutuhan manusia.Salah satunya melalui fungsi Transfer Risk, Risk Based Pricing dan sejenisnya.Pada fungsi asuransi dapat pula mendorong perekonomoian negara dimana dapat mendorong pelaku industri atau perusahaan dalam perkembangan bisnisnya. Asuransi termasuk kedalam golongan Industri Keuangan Non Bank atau IKNB.Dilansir melalui laman OJK, terdapat hampir lebih dari 1000 unit usaha IKNB. Mengacu pada tabel dibawah ini, jumlah pelaku atau unit usaha dalam bidang asuransi masih jauh dari jumlah unit usaha yang lain, angka tersebut bahkan belum menyentuh $10 \%$ dari total keseluruhan pelaku IKNB di Indonesia. Apalagi kalau dibandingkan dengan perkembangan asuransi syariah yang hanya ada 13 dari 152 pelaku asuransi di Indonesia.

Tabel 1.

\section{Jumlah Pelaku Industri Keuangan Non}

Bank (Asuransi)

\begin{tabular}{|l|c|c|c|}
\hline \multirow{2}{*}{ Komponen } & \multicolumn{2}{|c|}{ Desember 2017 } & \multirow{2}{*}{ Total } \\
\cline { 2 - 4 } & Konvensional & Syariah & 152 \\
\hline Asuransi & 139 & 13 & 15 \\
\hline $\begin{array}{l}\text { Asuransi } \\
\text { Jiwa }\end{array}$ & 54 & 7 & 61 \\
\hline $\begin{array}{l}\text { Asuransi } \\
\text { Umum }\end{array}$ & 74 & 5 & 79 \\
\hline Reasuransi & 6 & 1 & 7 \\
\hline $\begin{array}{l}\text { Asuransi } \\
\text { Wajib }\end{array}$ & 3 & 0 & 3 \\
\hline $\begin{array}{l}\text { Asuransi } \\
\text { Sosial } \\
\text { (BPJS) }\end{array}$ & 2 & 0 & 2 \\
\hline
\end{tabular}

Sumber: Statistik Data Aset dan Pelaku IKNB OJK periode Desember 2017

Seiring dengan perkembangan zaman dari masa ke masa, asuransi pada dewasa ini memiliki berbagai macam jenis dan ragam.Dimulai dari dua tipe asuransi, yakni Syariah dan Konvesional.Kemudian terdapat perbedaan mendasar antara 
Suryoaji, et al/Jurnal Ekonomi Syariah Teori dan Terapan Vol. 6 No. 9 September 2019: 1877-1893; KOMPARASI EFISIENSI \& PRODUKTIVITAS PERUSAHAAN ASURANSI JIWA KONVENSIONAL DAN SYARIAH DI INDONESIA PADA TAHUN 2014 - 2017, DENGAN PENDEKATAN DEA \& INDEKS MALMQUIST

asuransi umum/kerugian dengan asuransi jiwa. (Sari, 2000:17) Asuransi Jiwa ialah yang memberikan jasa dalam penanggulangan resiko yang dikaitkan dengan hidup atau meninggalnya seseorang yang dipertaruhkan.Kembali mengacu pada tabel 1 mengenai jumlah peserta atau pelaku Asuransi terdapat 7 perusahaan asuransi Jiwa Syariah, sementara konvensional memiliki 54 perusahaan asuransi Jiwa. Sedangkan perusahaan asuransi umum konvensional terdapat 74 perusahaan, dibandingkan dengan jumlah perusahaan asuransi umum Syariah yang hanya terdapat 5 perusahaan.Dari data pada tabel diatas dapat diketahui bahwa perkembangan asuransi Jiwa dan Umum dalam sistem Syariah mengalami perbedaan, dimana masyarakat memilih lebih menggunakan asuransi berbasis sistem Syariah hanya untuk keperluan penanggungan resiko kematian saja.

(Assofi, 2017:2) Semakin efektif dan efisien aset perusahaan maka semakin cepat perputaran dana pada suatu perusahaan tersebut. Apabila semakin cepat perputaran dana perusahaan maka hal tersebut membuktikan tanda positif bahwa perusahaan mengalami kondisi keuangan yang baik, sehingga dapat melakukan peningkatan efisiensi atau produktivitas. $\mathrm{Hal}$ ini lah yang memengaruhi perkembangan perushaan asuransi jiwa baik konvensional maupun syariah, terutama daam hal efisiensi dan produktivitas perusahaan tersebut dalam menghasilkan profit.Penghitungan dalam mengukur produktivitas biasa menggunakan malmquist index yang telah menjadi banyak rujukan penelitian sebelumnya dalam menghitung produktivitas seperti dalam (Rakhmadi, 2010) tentang produktivitas perbankan di Indonesia, (Biener, 2016) mengenai produktivitas dan efisiensi Industri Asuransi di Swiss, (Barros, 2005) produktivitas perusahaan asuransi di Portugal, dan masih banyak lainnya yang turut menggunakan Indeks Malmquist.Produktivitas sendiri menurut (Rakhmadi, 2010:32) merupakan hubungan antara input dan output dalam sebuah produksi, dimana besaran input yang digunakan akan memengaruhi besaran output yang dikeluarkan. Sehingga yang dimaksud dengan produktivitas ialah dimana input yang sekecil atau seminim digunakan sehingga memeroleh ouput sebesar atau sebanyakbanyaknya (Avenzora, 2008:3 dalam Rakhmadi, 2010:32).

Sehinngga peneliti ingin membandingkan antara produktivitas yang terjadi pada asuransi Syariah dengan asuransi konvensional. Hal tersebut semakin mengarahkan peneliti untuk fokus dan memilih judul penelitian Komparasi Efisiensi \& Produktivitas Perusahaan Asuransi Jiwa Konvensional Dan Syariah Di Indonesia Pada Tahun 2014 - 2017, Dengan Pendekatan Dea \& Indeks Malmquist. 
Suryoaji, et al/Jurnal Ekonomi Syariah Teori dan Terapan Vol. 6 No. 9 September 2019: 1877-1893; KOMPARASI EFISIENSI \& PRODUKTIVITAS PERUSAHAAN ASURANSI JIWA KONVENSIONAL DAN SYARIAH DI INDONESIA PADA TAHUN 2014 - 2017, DENGAN PENDEKATAN DEA \& INDEKS MALMQUIST

Dari penelitian ini akan dapat diketahui antara asuransi umum konvensional atau Syariah yang memiliki tingkat produktivitas yang tinggi sehingga dapat menjadi instropeksi diri perusahaanperusahaan asuransi umum yang kurang produktif.

\section{LANDASAN TEORI PENGEMBANGAN HIPOTESIS}

Asuransi atau pertanggungan adalah perjanjian antara dua pihak atau lebih, dengan mana pihak penanggung mengikatkan diri kepada tertanggung, dengan menerima premi Asuransi, untuk memberikan penggantian kepada tertanggung karena kerugian, kerusakan atau kehilangan keuntungan yang diharapkan, atau tanggung jawab hukum kepada pihak ketiga yang mungkin akan diderita tertanggung, yang timbul dari suatu peristiwa yang tidak pasti, atau untuk memberikan suatu pembayaran yang didasarkan atas meninggal atau hidupnya seseorang yang dipertanggungkan (UU No. 2 tahun 1992 tentang Usaha PerAsuransian). Kemudian dalam Asuransi tentunya terdapat objek atau hal yang menjadi benda untuk dipertangguhkan seperti berupa benda dan jasa, jiwa dan raga, kesehatan manusia maupun tanggung jawab hukum, semua kepentingan lainnya yang dapat hilang, rusak, rugi, dan atau berkurang nilainya. Selanjutya fungsi dari adanya Asuransi adalah menggantikan atau memberikan ganti rugi atas hilangnya atau rusaknya suatu hal yang berharga bagi individu tersebut, dapat memberikan rasa aman kepada individu sebagai akibat dari barang atau objek yang dapat di ganti rugikan.Kemudian dapat berfungsi sebagai tabungan, penyebaran resiko, dan meningkatkan keberlangsungan usaha (Ari, 2013).

Adapun pengertian atau arti asuransi secara garis besar adalah kedua pihak yang membeli dan menjual resiko, salah satu pihak menanggung resiko berupa kerugian, kehilangan, kematian dan sebagainya atas pihak yang tertanggung dengan memeroleh premi asuransi dari pihak yang tertanggung. Beberapa prinsip-prinsip hukum dalam asuransi konvensional (Indra 2016:31) :

a. Personal nature (bersifat pribadi).

b. Conditional Nature (bersifat kondisional).

c. Strict Compliance nature (bersifat adhesi dengan kerelaan).

d. Indemenity nature (bersifat adanya pembatasan).

e. Insurable interest (adanya pihak yang berkepentingan terhadap manfaat pertanggungan).

f. Hak subrogasi, yaitu hak menagih ganti rugi kerugian kepada pihak yang menyebabkan terjadinya kerugian yang dilakukan oleh penangguung setelah ia melunasi kewajibannya pada tertanggung.

g. Concealment concept (konsep penyembunyian).

h. Reprecentation concept (konsep representasi). 
Suryoaji, et al/Jurnal Ekonomi Syariah Teori dan Terapan Vol. 6 No. 9 September 2019: 1877-1893; KOMPARASI EFISIENSI \& PRODUKTIVITAS PERUSAHAAN ASURANSI JIWA KONVENSIONAL DAN SYARIAH DI INDONESIA PADA TAHUN 2014 - 2017, DENGAN PENDEKATAN DEA \& INDEKS MALMQUIST

i. Warranties concept (konsep jaminan)

Sementara dalam Syariah, setiap orang yang memiliki kemampuan menjadi penjamin dengan suatu kebajikan bagi setiap potensi kemanusiaan dalam masyarakat sejalan dengan pemeliharaan kemashlahatan individu. Serta dalam beberapa literatur lain menjelaskan bahwa Asuransi Syariah lebih sering dikenal atau disebut dengan Asuransi takaful. Takaful sendiri secara etimologi adalah berasal dari kata takafulan dari bahasa Arab yang berarti saling menanggung atau saling menjamin (Muhammad Mas'un dalam Indra, 2016).Takaful menurut istilah yang berkaitan dengan Asuransi adalah saling memikul resiko di antara sesama orang sehingga antara satu dengan lainnya menjadi penanggung atas resiko yang terjadi.Dalam Asuransi Syariah terdapat dua akad yang digunakan dalam pelaksanaan fungsi Asuransi, yakni akad tabarru' dan tijarah.Akad tabarru' adalah semua bentuk akad yang dilakukan dengan tujuan kebaikan dan tolongmenolong. Tabarru' berasal dari kata (tabarra'a-yatabarra'u-tabarru'an) yang berarti sumbangan, hibah, dana kebajikan atau derma.

Perbedaan asuransi Konvensional dengan asuransi Syariah adalah terdapat pada banyak konsep, prinsip serta beberapa dasar hukum yang berlainan.Seperti pada konsep fundamental atau konsep dasar dalam berasuransi.

Konsep fundamental dalam asuransi Syariah, ialah usaha untuk melindungi serta tolong-menolong diantara sejumlah orang atau pihak melalui dana investasi dalam bentuk aset baik dalam tipe apapun juga (akad). Sementara pada asuransi Konvensional, asuransi termasuk dalam usaha jual beli antara peserta dan perusahaannya. Dalam (Novi, 2011:39) menjelaskan bahwa dalam hal ini asuransi Konvensional memiliki arti umum "jaminan" dan ada yang bertanggung jawab atas itu, yakni dalam hal ini adalah pihak perusahaan. Memberikan pembayaran atas kerugian atau kehilangan yang tertanggung, maka dalam hal ini jelas dapat dikatakan usaha asuransi Konvensional adalah jual beli atas peserta dengan perusahaan.

Di dalam sistem operasional asuransi Syariah, yang sebenarnya terjadi adalah saling bertanggung jawab, bantumembantu dan melindungi di antara para peserta sendiri.Perusahaan Asuransi diberi kepercayaan (amanah) oleh para peserta untuk mengelola premi, mengembangkan dengan jalan yang halal, memberikan santunan kepada yang mengalami musibah sesuai isi akta perjanjian tersebut. Pengelolaan resiko pada asuransi Syariah adalah berbagi resiko (risk sharing), resiko yang ditanggung bersama sesama peserta asuransi secara langsung sedangkan dalam asuransi Konvensional adalah (risk 
Suryoaji, et al/Jurnal Ekonomi Syariah Teori dan Terapan Vol. 6 No. 9 September 2019: 1877-1893; KOMPARASI EFISIENSI \& PRODUKTIVITAS PERUSAHAAN ASURANSI JIWA KONVENSIONAL DAN SYARIAH DI INDONESIA PADA TAHUN 2014 - 2017, DENGAN PENDEKATAN DEA \& INDEKS MALMQUIST

transfer) yaitu prinsip resiko dengan cara mentransfer atau memindahkan risiko peserta suransi ke perusahaan asuransi.

Keuntungan perusahaan Asuransi syariah diperoleh dari bagian keuntungan dana dari para peserta, yang dikembangkan dengan prinsip mudharabah musytarakah dan wakalah bil ujrah dalam akad mudharabah, para peserta Asuransi syariah berkedudukan sebagai pemilik modal dan perusahaan Asuransi syariah berfungsi sebagai yang menjalankan modal (mudharib) . Keuntungan yang diperoleh dari pengembangan dana itu dibagi antara para peserta dan perusahaan sesuai ketentuan yang telah disepakati. Sementara dalam perusahaan asuransi konvensional, keuntungan diperoleh dari tambahan premi atau imbalan premi yang dapat dikategorikan sama dengan bunga tetapi dikenakan pada premi asuransi yang jelas dalam perjanjian, kemudian diperoleh dari hasil investasi pada pihak ketiga.

Dalam penghitungan produktivitas mengalami perbedaan pula, Samuelson dan Nordhaus mengatakan bahwa produktivitas adalah suatu konsep yang mengukur rasio dari total output terhadap rata-rata tertimbang dari input, adapun dua varian penting adalah produktivitas tenaga kerja yang menghitung jumlah output perunit tenaga kerja dan produktivitas faktor total yang mengukur output perunit dari total input (Samuelson, 2003). Pada berbagai literatur, produktivitas ditemukan dalam berbagai rumusan, fungsi atau konsep.

$$
\text { Menurut sebagian ahli, }
$$

produktivitas berarti lebih banyak hasil atau output dengan mempertahankan biaya yang tetap, mengerjakan sesuatu yang benar, bekerja lebih cerdik dan lebih keras, atau pengoperasian secara otomatis untuk mendapatkan hasil yang lebih cepat (Putti, 1985 dalam Tita, 2011).Menurut (Rusydiana, 2015), hubungan tersebut dinyatakan rasio dari indeks output dengan beberapa input secara bersama-sama, jika rasio meningkat maka berarti lebih banyak output dapat diproduksi dalam jumlah input tertentu atau memroduksi lebih banyak output dengan input yang sedikit. Dalam pengukuran produktivitas, yang paling banyak dipakai oleh metode TotalFactorProductivity (TFP). Metode ini dipakai untuk mengatasi kelemahan perhitungan efisiensi yang lebih dari satu input dan satu output. TFP diukur dengan menggunakan angka indeks yang dapat mengukur perubuhan harga dan kuantitas sepanjang waktu.Selain itu TFP, juga mengukur perbandingan dan perbedaan antar entitas.

Maka dapat kita sepakati dan simpulkan bahwa produktivitas adalah perbandingan antara hasil yang dicapai (output) dengan keseluruhan sumber daya yang digunakan (input). Menurut (Umar, 1977 dalam Fathoni \& Ghozali, 2017:3); 
Suryoaji, et al/Jurnal Ekonomi Syariah Teori dan Terapan Vol. 6 No. 9 September 2019: 1877-1893; KOMPARASI EFISIENSI \& PRODUKTIVITAS PERUSAHAAN ASURANSI JIWA KONVENSIONAL DAN SYARIAH DI INDONESIA PADA TAHUN 2014 - 2017, DENGAN PENDEKATAN DEA \& INDEKS MALMQUIST

Bahwa produktivitas memiliki dua dimensi.Yang pertama ialah dimensi efektif yang mengarah pada pencapaian untuk kerja yang maksimal. Yaitu pencapaian target yang nerkaitan dengan kualitas, kuantitas, dan waktu. Yang kedua ialah dimensi efisiensi yang berkaitan dengan upaya membandingkan input dengan realisasi penggunaannya atau bagaimana pekerjaan tersebut dapat dilaksanakan.

"Tangan yang diatas lebih baik daripada dengan tangan yang dibawah" (Fathoni \& Ghozali, 2017:6) ungkapan tersebut sering kita dengar dari para tokoh Islam. Yang dapat berarti bekerja lebih baik dari pada hanya sekedar memintaminta atau mengemis pada orang lain. Namun pada kenyataannya muslim sekalian lebih banyak yang hanya mengandalkan uluran belas kasih pada orang lain. Mereka lebih memilih bermalas-malasan, dengan tidak mau bekerja dan memilih jalan mudah yang sama sekali tidak mencerminkan etos kerja yang baik.

Dalam surat Al Jumuah ayat 10, menerangkan bahwasannya, "Apabila telah ditunaikan shalat, maka bertebaranlah kamu di muka bumi; dan carilah karunia Allah dan ingatlah Allah banyak-banyak supaya kamu beruntung"

Semampang dengan ayat diatas, dapat ditelaah bahwa sebaik-baik manusia adalah yang mencari karunia Allah (dapat diartikan sebagai sumber kehidupan atau materi dan sumber daya dalam leberlangsungan hidup manusia) serta selalu mengingat Allah agar selalu mendapatkan ridha atau keberuntungan.Dari kata mencari, sesungguhnya hendaklah diartikan dengan bekerja atau memproduksi atau menghasilkan sesuatu bukan berarti menunggu.Yang memiliki makna tidak melakukan apa-apa selain dari menunggu karunia Allah datang sendiri kepadanya.

Produksi atau produktivitas tidak hanya melihat seberapa besar atau banyak output yang dihasilkan melainkan juga efisiensi dalam pengguanan input. (Pambudi, 2018:26) mengungkapkan bahwa suatu metode dikatakan lebih efisien apabila menggunakan sejumlah input yang sama namun dapat memeroleh output yang lebih atau sama banyaknya dengan asumsi harga input dan output sama pada kedua metode yang digunakan. Dalam asuransi dikatakan efisien apabila dapat menghasilkan output yang berupa pendapatan dan premi dengan input yang semakin sedikit tetapi menghasilkan output yang lebih banyak (Ningsih, 2017:34).

Dalam penelitian kali ini, akan menggunakan pendekatan nilai tambah sebab lebih meluas dan meneliti secara menyeluruh jika dibandingkan hanya dengan pendekatan intermediasi. Sehingga, variabel input dalam penelitian ini adalah total aset, beban dan klaim. Total aset dan beban merupakan proxy 
Suryoaji, et al/Jurnal Ekonomi Syariah Teori dan Terapan Vol. 6 No. 9 September 2019: 1877-1893; KOMPARASI EFISIENSI \& PRODUKTIVITAS PERUSAHAAN ASURANSI JIWA KONVENSIONAL DAN SYARIAH DI INDONESIA PADA TAHUN 2014 - 2017, DENGAN PENDEKATAN DEA \& INDEKS MALMQUIST

dari layanan intermediasi perusahaan asuransi dimana aset-aset perusahaan adalah hasil investasi dari dana-dana yang terkumpul. Serta beban terkait dengan seluruh beban perusahaan yang dapat mengurangi pendapatan perusahaan, sehingga dapat melakukan manajerial yang baik daam meningkatkan pendapatan perusahaan.Selanjutnya klaim adalah proxy atas fungsi perusahaan asuransi umum dalam layanan perlindungan dan mengelola risk pooling. Sehingga dapat menghasilkan surplus underwritting dan menambah dana premi bagi perusahaan.

Variabel output dalam penelitian ini adalah premi atau dana tabarru' (Asuransi Umum Syariah) dan pendapatan yang merupakan proxy dari ketiga layanan utama pada perusahaan asuransi. Penghimpunan premi atau dana tabarru' dalam melaksanakan fungsi risk pooling dan risk bearing serta memberikan layanan perlindungan kepada peserta dengan membayar klaim pemegang polis. Adapun dengan pendapatan yang didapatkan dari ketiga layanan perusahaan asuransi sendiri.

Penghitungan akan dilakukan menggunakan DEA dan Indeks Malmquist, DEA merupakan metode efisiensi frontier dengan pendekatan non-parametrik yang menggunakan model program linier untuk menghitung perbandingan rasio output dan input serta mengukur efisiensi relatif untuk semua unit yang diperbandingkan (Loka, 2015:34). Unit produksi dalam DEA disebut UPK atau DMU yang berarti Unit Pengambil Keputusan (Decision Making Unit), dimana skor efisiensi yang dihasilkan oleh DEA berkisar antara 0-100 persen atau 0-1. UPK $<1$ dianggap sebagai unit yang relatif efisien dibandingkan dengan unit-unit lainnya, serta sebaliknya apabila UPK >1 maka dianggap sebagai unit yang relatif tidak efisien.

(Sutawijaya, 2009 dalam Loka, 2015:34) mengatakan bahwa metode DEA dibagi menjadi dua model pendekatan berdsarkan hubungan input dan output -nya, yakni model CRS (Constant Return To Scale) dan VRS (Variable Return To Scale). Model CRS diasumsikan bahwa setiap UPK akan beroperasi pada skala pengembalian yang konstan. Dimana perubahan input proporsional atau sebanding dengan perubahan output. Sehingga penambahan input tidak berpengaruh terhadap penambahan atau pengurangan output dan produktivitas yang mungkin dicapai.

Sedangkan model VRS (Loka, 2015:35) merupakan model dimana semua unit yang diukur akan menghasilkan perubahan pada berbagai tingkat output atau bervariasi. Dengan kata lain UPK dianggap akan beroperasi pada skala pengembalian yang bervariasi. Sehingga jika ada penambahan input sebanyak $n$ kali, maka output tidak akan bertambah sebanyak $n$ kali (bisa lebih ataupun kurang dari $n$ kali). 
Suryoaji, et al/Jurnal Ekonomi Syariah Teori dan Terapan Vol. 6 No. 9 September 2019: 1877-1893; KOMPARASI EFISIENSI \& PRODUKTIVITAS PERUSAHAAN ASURANSI JIWA KONVENSIONAL DAN SYARIAH DI INDONESIA PADA TAHUN 2014 - 2017, DENGAN PENDEKATAN DEA \& INDEKS MALMQUIST

DEA dapat memberikan langkah teknis dalam efisiensi input-oriented atau outputoriented.

Dimana input-oriented adalah untuk mengurangi banyaknya input secara proporsional tanpa mengubah sejumlah output. Sedangkan outputoriented adalah penambahan output maksimal secara proporsional tanpa mengubah sejumlah input yang telah tersedia.

Indeks malmquist (Malmquist Productivity Index) adalah indeks yang menjelaskan tentang tingkat produktivitas perusahaan tertentu dengan mengukur fungsi produksi secara maksimum dengan batasan input yang sudah ditentukan. Indeks malmquist sebenarnya adalah salah satu dari metode DEA yang digunakan dalam mengolah data panel non-parametrik (Loka, 2015:36).

Sebelumnya dalan menggunakan pengukuran TFP, indeks yang sering digunakan adalah menggunakan Laspeyers Index, Pasche Index, Fisher Index, Tornvist Index, dan Malmquist Index. Penggunaan Indeks malmquist digunakan dalam penelitian ini karena indeks malmquist memiliki beberapa perihal keuntungan.Yakni, yang pertama adalah indeks mamlmquist merupakan metode non-parametrik sehingga tidak memerlukan spesifikasi bentuk fungsi produksi.Yang kedua adalah indeks ini tidak memiliki slope atau batas umum formula seperti minimum biaya ataupun maksimalisasi profit, sehingga sangat berguna apabila memiliki produsen yang berbeda-beda.Pada (Loka, 2015:37) dengan menggunakan metode Malmquist Index, maka hasil atau nilai indeks yang lebih besar dari satu $(M \mid>1)$ mengindikasikan bahwa UPK (Unit Pengambil Keputusan) tersebut mengalami peningkatan dalam total produktivitas. Namun jika sebaliknya $(M \mid<1)$ maka mengindikasikan bahwa UPK mengalami penurunan dalam total produktivitas.

\section{METODE PENELITIAN}

Pendekatan penelitian yang dilakukan atau dipakai dalam penelitian ini adalah menggunakan pendekatan penelitian kuantitatif.Periode analisa dilakukan pada tahun 2014 - 2017. variabel-variabel yang akan digunakan adalah:

1. Variabel input, merupakan variabel yang dicari dan menentukan dalam pengukuran atau penghitungan DEA dan Malmquist Index. Yakni meliputi total aset, beban dan pembayaran klaim asuransi Konvensional dan Syariah di Indonesia

2. Variabel output, merupakan hasil dalam proses produksi yang dapat berupa jasa atau barang dalam hal ini meliputi pendapatan dan premi / dana tabarru' perusahaan asuransi Konvensional maupun Syariah di Indonesia.

Data yang digunakan dalam penelitian ini adalah data time series, terhitung dari 2014 sampai dengan 2017 
Suryoaji, et al/Jurnal Ekonomi Syariah Teori dan Terapan Vol. 6 No. 9 September 2019: 1877-1893; KOMPARASI EFISIENSI \& PRODUKTIVITAS PERUSAHAAN ASURANSI JIWA KONVENSIONAL DAN SYARIAH DI INDONESIA PADA TAHUN 2014 - 2017, DENGAN PENDEKATAN DEA \& INDEKS MALMQUIST

dari seluruh perusahaan asuransi jiwa Konvensional maupun Syariah di Indonesia yang diperoleh dari Statistik Industri Keuangan Non Bank Otoritas Jasa Kevangan.Populasi dalam penelitian ini adalah terdiri dari beberapa perusahaan asuransi umum Konvensional maupun Syariah di Indonesia. Metode purposive sampling digunakan dalam penelitian ini. Yang artinya, pengambilan sampel yang memenuhi kriteria tertentu yang dikehendaki. Penentuan kriteria dikehendaki agar dapat menghindari spesifikasi yang salah dalam penentuan sampel dan berpengaruh dalam hasil penelitian. Kriteria sampel yang dikehendaki adalah perusahaan asuransi umum Konvensional dan Syariah, baik berbentuk usaha Full fledge atau Unit Usaha Syariah yang memiliki data lengkap bernilai positif yang berkaitan dengan variabel yang digunakan antara lain total aset, beban, klaim, premi/dana tabarru', dan pendapatan selama 2014 hingga 2017.

Dari kriteria diatas peneliti menemukan antara lain 10 perusahaan asuransi Syariah baik Full fledge maupun UUS (Unit Usaha Syariah), serta 19 perusahaan asuransi Konvensional, yakni :

A. Perusahaan Asuransi Jiwa Syariah:

1. PT. AJS AMANAH JIWA GIRI ARTHA (Full fledge)

2. PT. ASURANSI JIWA AL AMIN (FUll fledge)

3. PT. AIA FINANCIAL (UUS)
4. PT. ASURANSI ALLIANZ LIFE INDONESIA (UUS)

5. PT. ASURANSI JIWA CENTRAL ASIA RAYA (UUS)

6. PT. ASURANSI JIWA MANULIFE INDONESIA (UUS)

7. PT. PANIN DAI-ICHI LIFE (UUS)

8. PT. PRUDENTIAL LIFE ASSURANCE (UUS)

9. PT. TOKIO MARINE LIFE INSURANCE INDONESIA (UUS)

10. PT. GREAT EASTERN LIFE INDONESIA (UUS)

B. Perusahaan Asuransi Jiwa Konvensional:

1. PT. AIA FINANCIAL

2. PT. ASURANSI ALLIANZ LIFE INDONESIA

3. PT. BNI LIFE INSURANCE

4. PT. ASURANSI JIWA CENTRAL ASIA RAYA

5. PT. EQUITY LIFE INDONESIA

6. PT. GREAT EASTERN LIFE INDONESIA

7. PT. ASURANSI JIWA INDOSURYA SUKSES

8. PT. ASURANSI JIWA INHEALTH INDONESIA

9. PT. ASURANSI JIWA MANULIFE INDONESIA

10. PT. MNC LIFE ASSURANCE

11. PT. PANIN DAI-ICHI LIFE

12. PT. PRUDENTIAL LIFE ASSURANCE

13. PT. ASURANSI JIWA RELIANCE INDONESIA

14. PT. ASURANSI JIWA SEQUIS LIFE

15. PT. ASURANSI JIWA TASPEN

16. PT. TOKIO MARINE LIFE INSURANCE INDONESIA 
Suryoaji, et al/Jurnal Ekonomi Syariah Teori dan Terapan Vol. 6 No. 9 September 2019: 1877-1893; KOMPARASI EFISIENSI \& PRODUKTIVITAS PERUSAHAAN ASURANSI JIWA KONVENSIONAL DAN SYARIAH DI INDONESIA PADA TAHUN 2014 - 2017, DENGAN PENDEKATAN DEA \& INDEKS MALMQUIST

17. PT. ASURANSI JIWA TUGU MANDIRI

18. PT. AJ ADISARANA WANAARTHA

19. PT. ZURICH TOPAS LIFE

Penelitian menggunakan tekhnik penghitungan DEA secara VRS (Data Envelopment Analysis), dalam (Rakhmadi, 2010:32) memberikan pengartian bahwa DEA merupakan metode yang mengelompokan data observasi untuk membentuk frontier yang nantinya digunakan untuk mengevaluasi kinerja dari objek penelitian. Penilaian hasil evaluasi dari metode DEA memiliki range dari angka 0-1 dimana semakin mendekati 1 maka semakin efisien, sebaliknya jika mendekati angka 0 maka semakin inefisien (Cooper et al, 2006 dalam Rakhmadi, 2010:33).

Dalam pengukuran berorientasi input dan output dipilih agar dapat mengetahui kemampuan UPK dalam menghimpun input untuk perusahaan asuransinya serta maksimalisasi profit perusahaan. Untuk menyempurnakan penelitian ini, maka dipilih orientasi input dan output dalam penghitungan MI. Hasil penghitungan $\mathrm{Ml}$ yang berupa TFP, akan menghasilkan empat nilai komponen TFP meliputi, TEC (Technical Efficiency Change), TC (Technical Change), dan TFPC (Total Factor Productivity Change). Pada akhir perhitungan dikatakan DMU atau UPK mengalami produktivitas apabila UPK $\geq 1$, sebaliknya apabila UPK mengalami inefisien ketika UPK $<1$.

IV. HASIL DAN PEMBAHASAN
Dalam tabel 4.1 menjelaskan secara rinci mengenai nilai CRS, VRS, dan Scale Efficiency masing-masing perusahaan. Serta sesuai pada gambar-gambar sebelumnya, terbukti bahwa 5 perusahaan yang efisien memeroleh nilai 1 (UPK $=1$ ) pada tabel 4.3. Berdasarkan keseluruhan uraian diatas dapat disimpulkan bahwa perusahaan asuransi jiwa konvensional secara keseluruhan belum mencapai efisiensi ekonomi (CRS). Jumlah perusahaan asuransi konvensional yang efisien dalam CRS hanya 5 perusahaan, dimana artinya otomatis efisien dalam penghitungan VRS dan Scale Efficiency.Serta menunjukkan bahwa 5 perusahaan tersebut mengalami efisiensi selama kurun waktu 4 tahun mulai dari 2014 hingga 2017.

Tabel 2.

Daftar Rata-rata Efisiensi dan Inefisiensi

Perusahaan Asuransi Jiwa Konvensional

Secara CRS, VRS, dan Scale Efficiency

Orientasi Input dan Output pada Tahun

2014-2017

\begin{tabular}{|l|l|l|l|}
\hline Perusahaan & CRS & VRS & $\begin{array}{l}\text { Scale } \\
\text { Efficiency }\end{array}$ \\
\hline $\begin{array}{l}\text { PT. AIA } \\
\text { Financial }\end{array}$ & 0.963 & 1 & 0.963 \\
\hline $\begin{array}{l}\text { PT. Asuransi } \\
\text { Allianz Life } \\
\text { Indonesia }\end{array}$ & 1 & 1 & 1 \\
\hline $\begin{array}{l}\text { PT. BNI Life } \\
\text { Insurance }\end{array}$ & 0.941 & 0.984 & 0.956 \\
\hline $\begin{array}{l}\text { PT. Asuransi } \\
\text { Jiwa } \\
\text { Central }\end{array}$ & 0.904 & 1 & 0.904 \\
\hline
\end{tabular}


Suryoaji, et al/Jurnal Ekonomi Syariah Teori dan Terapan Vol. 6 No. 9 September 2019: 1877-1893; KOMPARASI EFISIENSI \& PRODUKTIVITAS PERUSAHAAN ASURANSI JIWA KONVENSIONAL DAN SYARIAH DI INDONESIA PADA TAHUN 2014 - 2017, DENGAN PENDEKATAN DEA \& INDEKS MALMQUIST

\begin{tabular}{|c|c|c|c|}
\hline Asia Raya & & & \\
\hline $\begin{array}{l}\text { PT. Equity } \\
\text { Life } \\
\text { Indonesia }\end{array}$ & 1 & 1 & 1 \\
\hline $\begin{array}{l}\text { PT. Great } \\
\text { Eastern Life } \\
\text { Indonesia }\end{array}$ & 1 & 1 & 1 \\
\hline $\begin{array}{l}\text { PT. Asuransi } \\
\text { Jiwa } \\
\text { Indosurya } \\
\text { Sukses }\end{array}$ & 0.955 & 0.966 & 0.989 \\
\hline $\begin{array}{l}\text { PT. Asuransi } \\
\text { Jiwa } \\
\text { Inhealth } \\
\text { Indonesia }\end{array}$ & 0.768 & 0.785 & 0.9795 \\
\hline $\begin{array}{l}\text { PT. Asuransi } \\
\text { Jiwa } \\
\text { Manulife } \\
\text { Indonesia }\end{array}$ & 0.798 & 0.806 & 0.99 \\
\hline $\begin{array}{l}\text { PT. MNC } \\
\text { Life } \\
\text { Assurance }\end{array}$ & 0.949 & 0.949 & 0.999 \\
\hline $\begin{array}{l}\text { PT. Panin } \\
\text { Dai-Ichi Life }\end{array}$ & 0.96 & 0.96 & 1 \\
\hline $\begin{array}{l}\text { PT. } \\
\text { Prudential } \\
\text { Life } \\
\text { Assurance }\end{array}$ & 0.839 & 0.931 & 0.901 \\
\hline $\begin{array}{l}\text { PT. Asuransi } \\
\text { Jiwa } \\
\text { Reliance } \\
\text { Indonesia }\end{array}$ & 0.825 & 0.909 & 0.907 \\
\hline $\begin{array}{l}\text { PT. Asuransi } \\
\text { Jiwa Sequis } \\
\text { Life }\end{array}$ & 0.819 & 0.836 & 0.979 \\
\hline $\begin{array}{l}\text { PT. Asuransi } \\
\text { Jiwa }\end{array}$ & 1 & 1 & 1 \\
\hline
\end{tabular}

\begin{tabular}{|c|c|c|c|}
\hline Taspen & & & \\
\hline $\begin{array}{l}\text { PT. Tokio } \\
\text { Marine Life } \\
\text { Indonesia }\end{array}$ & 1 & 1 & 1 \\
\hline $\begin{array}{l}\text { PT. Asuransi } \\
\text { Jiwa Tugu } \\
\text { Mandiri }\end{array}$ & 0.996 & 1 & 0.996 \\
\hline $\begin{array}{l}\text { PT. Asuransi } \\
\text { Jiwa } \\
\text { Adisarana } \\
\text { Wanaartha }\end{array}$ & 0.978 & 0.993 & 0.984 \\
\hline $\begin{array}{l}\text { PT. Zurich } \\
\text { Topas Life }\end{array}$ & 0.992 & 1 & 0.992 \\
\hline
\end{tabular}

Tabel 3.

Daftar Rata-rata Efisiensi dan Inefisiensi Perusahaan Asuransi Jiwa Syariah Secara CRS, VRS, dan Scale Efficiency Orientasi Input dan Output pada Tahun 2014-2017

\begin{tabular}{|l|l|l|l|}
\hline Perusahaan & CRS & VRS & $\begin{array}{l}\text { Scale } \\
\text { Efficiency }\end{array}$ \\
\hline $\begin{array}{l}\text { PT. Ajs } \\
\text { Amanah } \\
\text { Jiwa Giri } \\
\text { Artha }\end{array}$ & 0.764 & 1 & 0.764 \\
\hline $\begin{array}{l}\text { PT. Asuransi } \\
\text { Jiwa Al- } \\
\text { Amin AIA }\end{array}$ & 0.622 & 1 & 0.622 \\
\hline $\begin{array}{l}\text { PT. } \\
\text { Financial } \\
\text { (UUS) }\end{array}$ & 1 & 0.805 \\
\hline $\begin{array}{l}\text { PT. Asuransi } \\
\text { Allianz Life } \\
\text { Indonesia } \\
\text { (UUS) }\end{array}$ & 0.734 & 1 & 0.734 \\
\hline PT. Asuransi & 0.834 & 0.926 & 0.9 \\
\hline
\end{tabular}


Suryoaji, et al/Jurnal Ekonomi Syariah Teori dan Terapan Vol. 6 No. 9 September 2019: 1877-1893; KOMPARASI EFISIENSI \& PRODUKTIVITAS PERUSAHAAN ASURANSI JIWA KONVENSIONAL DAN SYARIAH DI INDONESIA PADA TAHUN 2014 - 2017, DENGAN PENDEKATAN DEA \& INDEKS MALMQUIST

\begin{tabular}{|l|l|l|l|}
\hline $\begin{array}{l}\text { Jiwa } \\
\text { Central } \\
\text { Asia Raya } \\
\text { (UUS) }\end{array}$ & & & \\
\hline $\begin{array}{l}\text { PT. Asuransi } \\
\text { Jiwa } \\
\text { Manulife } \\
\text { Indonesia } \\
\text { (UUS) }\end{array}$ & 0.845 & 0.933 & 0.904 \\
\hline $\begin{array}{l}\text { PT. Panin } \\
\text { Dai-Ichi Life } \\
\text { (UUS) }\end{array}$ & 0.855 & 0.948 & 0.902 \\
\hline $\begin{array}{l}\text { PT. } \\
\text { Prudential } \\
\text { Life } \\
\text { Assurance } \\
\text { (UUS) }\end{array}$ & 0.833 & 0.911 & 0.914 \\
\hline $\begin{array}{l}\text { PT. Tokio } \\
\text { Marine Life } \\
\text { Indonesia } \\
\text { (UUS) }\end{array}$ & 1 & 1 & 1 \\
\hline $\begin{array}{l}\text { PT. Great } \\
\text { Eastern Life } \\
\text { Indonesia } \\
\text { (UUS) }\end{array}$ & 1 & 1 & 1 \\
\hline $\begin{array}{l}\text { Sumber: Lampiran V Skripsi } \\
\text { data diolah kembali }\end{array}$ & & \\
\hline Dalam & & \\
& & & \\
\hline & & & \\
\hline
\end{tabular}

Dalam tabel 3 secara rinci dituliskan masing-masing nilai rata-rata CRS, VRS, dan Scale Efficiency perusahaan asuransi jiwa syariah tahun 2014-2017, bahwa memang terbukti benar PT. Tokio Marine Life Indonesia (UUS) dan PT. Great Eastern Life Indonesia (UUS) termasuk dalam kondisi efisiensi ekonomi. Sehingga kedua perusahaan tersebut mampu memanfaatkan input dan memaksimalkan output.

Hasil akhir dari penghitungan efisiensi DEA metode VRS orientasi input dan output pada 10 perusahaan asuransi jiwa syariah, baik full fledge maupun UUS di Indonesia pada tahun 2014-2017 ialah inefisiensi. Sebab hanya terdapat 2 perusahaan yang memeroleh efisiensi ekonomi, sehingga tidak dapat merepresentasikan kondisi perusahaan asuransi jiwa syariah lainnya yang cenderung inefisiensi.

Dalam penghitungan DEA Malmquist Index, diperoleh 5 komponen dasar perubahan TFP (Total Factor Productivity). Yakni effch (technical efficiency change) atau TEC, techch (technological change) atau TC, pech (pure technical efficiency change) atau PTEC, sech (scale efficiency change) atau SEC, dan tfpch (total factor productivity change) atau TFPC. Dalam penghitungan ini berorientasi terhadap input dan output, sehingga dapat memerhatikan dan menyempurnakan hasil penelitian ini.Dan didapati, rata-rata nilai TFPC keduanya (input-output) sebesar 1.049 yang berarti telah mengalami produktivitas.

Hal ini berarti dapat benar-benar menyimpulkan bahwa produktivitas pada perusahaan asuransi jiwa konvensional pada tahun 2014-2017 telah terlaksana bahkan mengalami peningkatan (1.049 $\geq$ 1). Sementara Syariah mendapat, ratarata nilai TFPC (input-output) sebesar 0,906.Maka dengan ini kesimpulannya adalah keseluruhan perusahaan asuransi 
Suryoaji, et al/Jurnal Ekonomi Syariah Teori dan Terapan Vol. 6 No. 9 September 2019: 1877-1893; KOMPARASI EFISIENSI \& PRODUKTIVITAS PERUSAHAAN ASURANSI JIWA KONVENSIONAL DAN SYARIAH DI INDONESIA PADA TAHUN 2014 - 2017, DENGAN PENDEKATAN DEA \& INDEKS MALMQUIST

jiwa syariah belum mengalami produktivitas. Sebab hanya satu atau dua perusahaan yang telah mengalami produktivitas, jumlah yang lebih banyak adalah yang belum mengalami produktivitas. Hal ini menunjukkan bahwa iklim atau kondisi perasuransian jiwa syariah belum mencapai produktivitas.

\section{SIMPULAN}

Berdasarkan dalam pembahasan serta hasil penelitian yang diperoleh maka dapat disimpulkan bahwa Jumlah perusahaan asuransi jiwa konvensional lebih banyak dibandingkan dengan perusahaan asuransi jiwa syariah di Indonesia pada tahun 2014-2017, kemudian perusahaan asuransi konvensional yang mengalami efisiensi dari tahun 2014 hingga 2017 adalah PT. Asuransi Allianz Life Indonesia, PT. Equity Life Indonesia, PT. Great Eastern Life Indonesia, PT. Asuransi Jiwa Taspen, dan PT. Tokio Marine Life Indonesia.Keseluruhan perusahaan asuransi jiwa konvensional mengalami inefisiensi dengan rasio 6:19 artinya hanya 6 dari 19 perusahaan asuransi jiwa konvensional yang mengalami efisiensi. Selanjutnya, Perusahaan asuransi syariah yang mengalami efisiensi dari tahun 2014 sampai dengan 2017 adalah PT. Tokio Marine Life Indonesia (UUS) dan PT. Great Eastern Life Indonesia (UUS).Keseluruhan perusahaan asuransi jiwa syariah mengalami inefisiensi dengan rasio 2:10 artinya hanya 2 dari 10 perusahaan asuransi jiwa syariah yang mengalami efisiensi.

Komparasi efisiensi perusahaan asuransi jiwa konvensional dan syariah membuktikan bahwa keduanya masuk dalam kondisi inefisiensi dari tahun 2014 sampai dengan 2017.Kemudian dalam produktivitas perusahaan asuransi jiwa konvensional yang tidak mengalami produktivitas adalah PT. Asuransi Jiwa Indosurya Sukses dan PT. MNC Life Assurance.Keseluruhan perusahaan asuransi jiwa konvensional mengalami peningkatan produktivitas dari tahun 2014 hingga 2017 dengan rata-rata nilai TFPC 1.049 serta rasio 2:19 artinya hanya terdapat 2 dari 19 perusahaan asuransi jiwa konvensional yang tidak mengalami produktivitas

Sementara, perusahaan asuransi jiwa syariah yang tidak mengalami produktivitas adalah PT. Asuransi Jiwa Al Amin (Fullfledge), PT. Asuransi Allianz Life Indonesia (UUS), PT. Asuransi Jiwa Central Asia Raya (UUS), PT. Asuransi Jiwa Manulife Indonesia (UUS), PT. Prudential Life Assurance (UUS), PT. Tokio Marine Life Indonesia (UUS) dan PT. Great Eastern Life Indonesia (UUS).Keseluruhan perusahaan asuransi jiwa syariah tidak mengalami peningkatann produktivitas dengan rasio 3:10 artinya hanya 3 dari 10 perusahaan asuransi jiwa syariah yang mengalami produktivitas dari tahun 2014-2017

$$
\text { Komparasi produktivitas }
$$

perusahaan asuransi jiwa konvensional dan syariah membuktikan bahwa 
Suryoaji, et al/Jurnal Ekonomi Syariah Teori dan Terapan Vol. 6 No. 9 September 2019: 1877-1893; KOMPARASI EFISIENSI \& PRODUKTIVITAS PERUSAHAAN ASURANSI JIWA KONVENSIONAL DAN SYARIAH DI INDONESIA PADA TAHUN 2014 - 2017, DENGAN PENDEKATAN DEA \& INDEKS MALMQUIST

perusahaan asuransi jiwa konvensional di Indonesia mengalami produktivitas pada tahun 2014-2017 sedangkan perusahaan asuransi jiwa syariah tidak mengalami produktivitas

Berdasarkan simpulan diatas maka peneliti dapat menyarankan perlunya dilakukan kebijakan internal yang cepat dan tepat sehingga dapat menjadikan perusahaan asuransi jiwa syariah lebih efisien, perlunya dilakukan perbaikan pada proses pengelolaan dana sehingga dapat memaksimalkan output dan meminimalisir input. Selain itu peningkatan skala usaha pada marketshare di Indonesia sehingga dapat bersaing dengan asuransi jiwa konvensional, dalam hal ini juga harus dilakukan secara berkala atau bersambung.Sehingga perusahaan asuransi jiwa syariah dapat mengalami kondisi produktivitas dari tahun ke tahunnya. Begitu pula dengan asuransi jiwa konvensional agar dapat melakukan hal yang sama dalam perbaikan pengelolaan dana serta variassi produk yang dapat menarik lebih banyak nasabah.

Dukungan dari pemerintah sangat dibutuhkan dalam hal regulasi, strategi dan jaringan pengembangan program asuransi jiwa syariah, dapat berupa sosialisasi serta campaign tentang asuransi jwa syariah itu sendiri sehingga dapat menambah peluang marketshare perusahaan asuransi jiwa syariah.Serta asuransi konvensional sehingga dapat memertahankan kondisi marketshare nya dan dapat memertahankan kondisi produktivitas.

Bagi peneliti yang ingin melakukan penelitian dengan tema yang sama dimasa yang akan dating hendaknya mengambil atau memilih secara lebih spesifik antara asuransi jiwa syariah atau konvensional dahulu agar penelitiannya dapat lebih menyeluruh dan terfokus pada objek yang satu. Sehingga diharapkan dari penelitian ini dapat menghasilkan penelitian yang lebih mendalam antara asuransi jiwa syariah dan konvensional, yang meliputi analisis efisiensi nya dan analisis produktivitasnya yang dibahas secara detail dan menyeluruh. Serta dapat melakukan pendekatan yang berbeda selain dari DEA ataupun Indeks Malmquist.simpulan simpulan

\section{DAFTAR PUSTAKA}

Al Qur'an

Barros, Carlos Pestana, Nazare Barroso and Maria Rosa Borges. 2005. Evaluating The Efficiency and Productivity of Insurance Companies with a Malmquist Index: A Case Study for Portugal. The Geneva Papers: 30 (244-267)

Biener, Christian, Martin Eling \& Jan Hendrik Wirfs. 2016. The Determinants Of Efficiency and Productivity In The Swiss Insurance Industry. ELSEVIER European Journal of Operational Research: 703-714 
Suryoaji, et al/Jurnal Ekonomi Syariah Teori dan Terapan Vol. 6 No. 9 September 2019: 1877-1893; KOMPARASI EFISIENSI \& PRODUKTIVITAS PERUSAHAAN ASURANSI JIWA KONVENSIONAL DAN SYARIAH DI INDONESIA PADA TAHUN 2014 - 2017, DENGAN PENDEKATAN DEA \& INDEKS MALMQUIST

Fathoni, Khoirul, Mohammad Ghozali. 2017. Analisis Konsep Produktivitas Kerja Konvensional Dalam Pandangan Islam. Al-Tijarah: Vol. 3 No. 1

Fidhayanti, Dwi. 2012. Pelaksanaan Akad Tabrru' Pada Asuransi Syariah (Studi di Takaful Indonesia Cabang Malang). Jurisdictie, Jurnal Hukum dan Syariah: Vol. 3 No. 1

Hasanah, Uswatun. 2013. Asuransi Dalam Perspektif Islam. Asy-Syir'ah: Vol. 47 No. 1

Hidayatullah, Indra. 2016. Sejarah, Prinsip, dan Perbedaan Antara Asuransi Takaful/Asuransi Syari'ah dan Asuransi Konvensional. lqtishoduna: Vol. 8 No. 2

Maksum, Muhammad. 2011. Pertumbuhan Asuransi Syariah di Dunia dan Indonesia. Al-lqtishad: Vol. III No. 1

Nurwidiatmo. 2008. Analisis dan Evaluasi Hukum Tentang Perasuransian (Asuransi Syariah) UU No. 2 Tahun 1992. Jakarta: Departemen Hukum dan Hak Asasi Manusia RI

Puspitasari, Novi. 2011. Sejarah dan Perkembangan Asuransi Islam Serta Perbedaannya dengan Asuransi Konvensional. JEAM: Vol. X No.11

Raharjo, Ari. 2013. Asuransi Konvensional dan Syariah. Jakarta

Rakhmadi, Rezki Syahri. 2010. Analisis Efisiensi dan Produktivitas Perbankan Syariah Di Indonesia.
Jakarta: Fakultas Ekonomi dan Bisnis UIN Syarif Hidayatullah

Sari, Kartika. . Sistem Informasi Asuransi: Pengenalan Assuransi. Depok: Universitas Gunadarma Surjaningsih, Ndari, Bayu Panji Permonno. 2014. Dinamika Total Factor Productivity Industri Besar dan Sedang di Indonesia. Jakarta: Buletin Ekonomi Moneter dan Perbankan

Yulianti, Rahmani Timorita. 2008. Asas-asas Perjanjian (Akad) dalam Hukum Kontrak Syariah. La Riba: Vol. II No. 1

2017. Statistik Asuransi. Jakarta: Otoritas Jasa Kevangan 2017. Daftar Izin Unit Usaha Syariah Perusahaan Asuransi Jiwa. Jakarta: Otoritas Jasa Kevangan

http://amanahgitha.com/laporankeuangan/. Diakses pada 28/10/18 http://alamin-insurance.com/laporankeuangan/. Diakses pada 28/10/18 https://asuransireliance.com/id/laporankevangan/. Diakses pada 15/11/18 http://www.aia-financial.co.id/id/aboutaia/company-report.html. Diakses pada $15 / 11 / 18$

https://www.allianz.co.id/tentangkami/Finansial. Diakses pada $15 / 11 / 18$

https://www.bni-life.co.id/id/laporantahunan. Diakses pada 15/11/18 http://www.car.co.id/id/tentangkami/profile/laporan-keuangan. Diakses pada 15/11/18 
Suryoaji, et al/Jurnal Ekonomi Syariah Teori dan Terapan Vol. 6 No. 9 September 2019: 1877-1893; KOMPARASI EFISIENSI \& PRODUKTIVITAS PERUSAHAAN ASURANSI JIWA KONVENSIONAL DAN SYARIAH DI INDONESIA PADA TAHUN 2014 - 2017, DENGAN PENDEKATAN DEA \& INDEKS MALMQUIST

http://www.equity.co.id/laporankeuangan. Diakses pada 15/11/18 https://www.greateasternlife.com/id/in/te ntang-kami/pusat-media/laporantahunan.html. Diakses pada $15 / 11 / 18$

http://www.indosuryalife.co.id/about/fina ncial_report. Diakses pada $15 / 11 / 18$

https://www.inhealth.co.id/id/gcg\#financi al_report. Diakses pada 15/11/18 https://www.manulife-

indonesia.com/Assets/Contents/La poranKeuangan/LaporanTahunan /Annual\%20Report\%202017\%20Fina 1\%2022052018.pdf. Diakses pada $15 / 11 / 18$

https://www.mnclife.com/about/report.

Diakses pada 15/11/18

http://www.ojk.go.id/id/kanal/iknb/datadan-

statistik/asuransi/Pages/Statistik-

Asuransi---November-2017.aspx.

Diakses pada 17/10/18

http://www.ojk.go.id/id/kanal/syariah/dat a-dan-statistik/iknbsyariah/Pages/Statistik-IKNBSyariah-Periode-November2017.aspx. Diakses pada 19/10/18 https://www.panindaiichilife.co.id/en/laporankeuangan. Diakses pada 15/11/18 https://www.prudential.co.id/id/ourcompany/financial-statement/. Diakses pada 15/11/18

https://www.sequis.co.id/en/aboutsequis/life/company-report. Diakses pada 15/11/18

https://www.sequis.co.id/id/tentangsequis/life/laporan-perusahaan. Diakses pada 15/11/18 https://www.taspenlife.com/index.php? $p=$ lapkeuangan. Diakses pada $15 / 11 / 18$

https://www.tokiomarine.com/id/id/about -us/life-insurance/financialinformation.html. Diakses pada $15 / 11 / 18$

https://www.tugumandiri.com/laporankeuangan. Diakses pada 15/11/18 http://www.wanaarthalife.com/id/wanaar tha-update/financial-report. Diakses pada 15/11/18

https://www.zurich.co.id/id-id/tentangkami/perusahan-asuransiglobal/zurich-topas-life/laporankeuangan. Diakses pada 15/11/18 https://www.zurich.co.id/id-id/tentangkami/perusahan-asuransiglobal/zurich-topas-life/laporantahunan. Diakses pada 15/11/18 http://www.worldbank.org/in/country/ind onesia/publication/indonesiaeconomic-quarterly-october-2017. Diakses pada 08/09/18 